Journal Plus Education, ISSN: 1842-077X, E-ISSN (online) 2068-1151 Vol XIX (2018), No. 1. pp. 249-261

\title{
SOCIAL WORK AND SEXUAL EDUCATION IN SCHOOL
}

\author{
Alina Maria BREAZ, PhD \\ „Aurel Vlaicu" University Arad \\ Mihaela TOMIŢĂ, Ph.D., \\ Universitatea de Vest din Timișoara \\ mihaela.tomita@e-uvt.ro
}

\begin{abstract}
Sexual education in schools is a matter of first importance in our country, considering that statistics show that every year one hundred thousand young girls make an abortion and there are a million sexually transmitted diseases every year. Therefore, for a good physical and mental health of the new generation, adequate sexual education is required, especially in high schools, which involve an interdisciplinary team: school physician, school psychologist, social worker. The paper makes a study on adolescent information levels based on a 20-question questionnaire applied to 100 high school students aged 15-19, girls and boys. The questions of the questionnaire refer to the level of sexual education of the young, the relationship with parents (in relation to sexuality), the way the school engages in this education, the responsibility and the level of satisfaction of the teenagers for the interest shown by the parents and the professors/education system on this issue. The results obtained in the questionnaire make us think that setting up counseling centers on sex life issues could clearly contribute to improve the future social and family adaptation of adolescents, leading to a decrease in the number of abortion and divorces over time.
\end{abstract}

Key words: adolescents; responsibility; sexual counseling; sexual education;

\section{Theoretical frame}

Considered one of the most tumultuous periods of life, adolescence offered a very complex study material. Adolescence is the age at which the individual has to take their lives in their own hands. As a continuation of puberty, it raises the problems of the previous stage to a higher scale. It is the age of the greatest performances, the energies being fully released.

The needs of the teenager are, on the one hand, generated by the needs they feel from the new perspective they are in, but there are other needs that have evolved from earlier times and have acquired a new form 
due to the new situation in which the individual is. The needs of the teenager take on a number of forms such as: the need for creativity with social value, affective reciprocity, the need to share feelings, the need for elective friends.

The social, economic and cultural differences influence the relationships between parents and children, the communication between them, the skills and the capacities of the relationship, the need to know the social and individual evolution of the teenager. The "parent profession" is an extremely difficult, demanding and dynamic one. Parents play a decisive role in acquiring the sense of stable and lasting identity. It has been found that adolescents who are less well-adapted and present a wide range of psychological problems have been the subject of parental rejection rather than acceptance and love.

Adolescence is a period of major changes, each of which produces a source of stress, the adolescent's famous crises, or various behavioral disorders. All these transformations, which arise as a result of development during this period, prepare the teenager to experience new types of behaviors. This experiment leads to risk-taking behaviors which, within certain limits, can be considered as a normal component of adolescent development (Moldovan, Balas-Timar, 2010) contributing to: defining their own identity, testing new skills, exercising decisional autonomy, developing the realistic self-evaluation capacity of one's own person, gaining respect and acceptance from the group of peers (Modrea, 2006).

Generally, adolescents take risks, but they need guidance and counseling to guide risk behaviors towards more constructive and less dangerous behaviors. The more he matures, the better he learns how to realistically assess the risk and modify his behavior based on perceived risk.

However, there are times when many of the risks posed by adolescents may pose real threats to their physical and mental health. This includes pregnancy, drug and alcohol abuse, smoking, as well as accidents involving various vehicles and devices (cars, bicycles, skateboards etc.). In the case of adolescents who constantly engage in risky behaviors, this fact may signal a deeper problem (Dinca, 2004).

Regardless of the society in which they live, children consider their parents responsibleto meet their wishes and needs, to ensure their successes or their failures. Relationships between parents and children are based on a special, socially filtered communication mechanism, in which a particular pattern, a pattern of conduct is achieved. Within these relationships, parents try, and often many of them succeed, to ensure the socialization of children, to contribute to the modification and improvement of the interrelation style developed in childhood (Verza, 2000).

If, during childhood, parents are the ones who effectively initiate the child in establishing family relationships, then extended to the playgroup, 
during adolescence, parents fail to supervise the teenager only with great difficulty. In childhood purchasing toys, nutrition, cleanliness, conversation is the exclusive benefit of the adult. Parents speak and transmit enormously to the child during their little childhood; in turn, they actually learn to talk, to engage in dialogue with their child.

Children ask questions that parents should try to answer and provide answers as appropriate as possible to the child's mental development. In adolescence, young people aspire to a status other than the "child": in their turn parents need to learn what and how to communicate with their son or daughter (Golu, 2015).

\section{Implications of poor communication}

When children are rejected by their parents, they dramatically increase their chances of evolving into puberty and adolescence towards delinquency, aggression, neurotic behavior, atypical behavior and, at the same time, their chances of turning to civilized behavior, being friendly, having civilized behavioral abilities, being cooperative, caring for others etc. are much lower (Hoyle, 2014).

During this period, the teenager faces the issue of sexual choice. R. Driscoll et al. (cited by Popa-Velea, 2013) studied the consequences of parents' intervention in order to control the love affections of their children and call into debate the so-called „Romeo and Juliet effect”. Non-acceptance of parents for adolescent choices may cause different reactions:

- Submission to the desire of adults and renunciation of a heterosexual choice: manifests shyness and inhibition of the opposite sex.

- Family Breakup: early marriages of youngsters escaping from an aggressive, anxious family environment.

- Choosing a partner according to the parents' image: the boy chooses a maternal wife in front of whom he gives up his responsibilities, the daughter falls in love with a seducer of his father's age.

Parents should know to engage and address with all responsibility these affective delicate periods that teenagers cross over to give them real help. This task is all the more difficult, as the teenager, pudic, considers any attempt of dialogue as an abusive interference in his intimate problems .

Development during adolescence is strongly marked by biological factors. From this point of view, biology offers the "physical" mechanism, and the hormonal factor offers the predisposition to act sexually. However, it is the social factors that give the outline of sexual behavior. There are three main areas where socialization of adolescent sexual behavior occurs: sexual identity, parental influence and the influence of those of the same age (Fodoreanu, 2004).

Sexual identity. This is one of the most important factors in socializing sexual behavior and acquiring gender identity. It refers to features such as 
masculinity and femininity; the roots are found in childhood, but their manifestation is plenary in adolescence, when adolescents learn about gender identity through the media, school and, most importantly, the parents and family they belong to.

Parental Influence. Parents express their own sexual attitude indirectly, by way of example of their own behavior, or in the context of wider aspects. In families in middle classes, parents are aware of principles such as selfcontrol, restraint, and postponement of gratification in general. For young people in families with a better economic and educational level, the probability of engaging in sexual intercourse at an early age is lower (Galimard, 2015).

Influence of the same age group. The influence of the group is one of the stronger forces behind sexuality in adolescence; the group provides information and values that are transmitted through group culture (Moldovan, Bălaş-Timar, 2010); In a survey conducted among adolescents, they were asked why they did not wait until they were raised to engage in sexual intercourse. Their answers point to several key motivations, with direct reference to group and group culture.

In summary, the socialization of adolescent sexual behavior is a learning process in which their own sexual identity, the parental influence and the influence of those of the same age interfere. Each dimension of sexual socialization goes through a complex process of training within a complex system of attitudes and behaviors, social standards and the requirement to comply with them (David, 2014).

\section{The research}

The research made is a pilot research aimed at establishing the level of adolescent knowledge related to life and sexual relations, as well as the relationships of young people with their parents and their attitudes towards certain aspects and consequences of sexual life. Depending on the results, the usefulness of setting up special sexual counseling rooms, where adolescents can discuss these aspects of life, with professionals (social workers, psychologists, doctors, etc.), is proven or not.

\section{A.Hypothesis}

The starting hypothesis was the following: If we know the level of knowledge about sexual life, of the adolescents then appropriate measures can be implemented to avoid increased risks in this area.

\section{B. The lot in the study}

In order to verify the research hypothesis, it was decided to study one class each year of high school. In total the lot numbered 100 subjects, 9th to 
12th grade students, from "Vasile Goldiş" High School in Arad, 43 boys and 57 girls.

\section{Working methodology}

\section{A. Methods}

It was built a questionnaire consisting of 20 questions. Questions had predetermined answers, but a number of 3 questions left a response ("others") where the subjects were able to offer other variants that were did not include in the questionnaire or give some explanations. Questionnaire questions related to aspects of sexual life, teenagers 'knowledge of it, their relationships with parents, adolescents' attitudes to questions asked, their sources of information etc.

\section{B. Conducting research}

The questionnaire was applied in the morning, during the hours provided by the teachers and the school's direction. The subjects were asked to respond with the highest degree of sincerity to the questions of the questionnaire, ensuring their confidentiality. To ensure greater sincerity, confidentiality was also ensured by the fact that the names of the subjects were not required, but only age, sex and class. In this way, it was hoped to get as honest as possible answers that would not be influenced by the phenomenon of social desirability.

The questionnaire operator was permanently present during the questionnaire completion, being prepared to provide explanations and guidance to adolescents in cases where the questions were not correctly understood. Once the questionnaires were completed, the results were processed and the subjects' answers were synthesized in tables and graphs. Subsequently, they were interpreted in the light of the literature and the theoretical context previously set out.

There were no cases in which the questionnaire was refused, although there were cases when the subjects did not answer to one or more questions. These cases were also included in the processing of results, under the heading "do not respond" and their interpretation was attempted to understand the motivation of the absence of answers from the subjects. 


\section{Results and discussions}

Most adolescents discussed at least once with one of the parents about intimate relationships (see Table 1 and Fig. 1).

Table 1. Discussing intimate relationship with parents

\begin{tabular}{|c|c|c|}
\hline & Yes & No \\
\hline 9th grade & 16 & 6 \\
\hline 10th gade & 18 & 9 \\
\hline 11th grade & 20 & 2 \\
\hline 12th grade & 22 & 5 \\
\hline
\end{tabular}

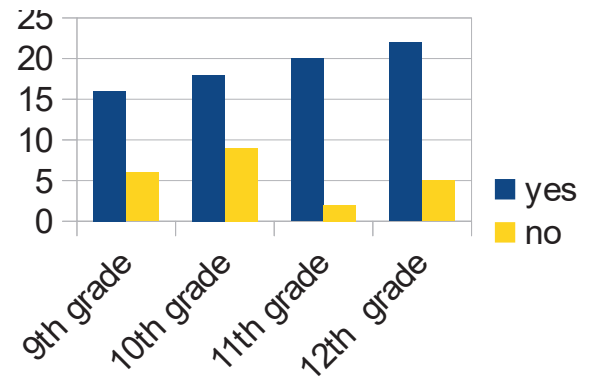

Fig. 1. Discussing intimate relationships with parents

Although the vast majority of adolescents have discussed with one of the parents at least once about intimate relationships, one can still see a difference from the 9th grade to the 11th-12th grades. With psychoemotional maturation and strengthening of personality traits, adolescents no longer feel "shameful" to talk with their parents about their intimate relationships. In smaller grades (9th and 10th), the number of young people who do not discuss with their parents this aspect of their lives is greater. Perhaps they consider intimate relationships to be a private subject that the parents do not care and at the same time have not yet acquired the easiness of addressing this subject with a mature person. There are some reminiscences from the previous period, when such a subject should not, in any case, reach the ears of the parents.

Frequency of discussions with parents about the intimate relationship is shown in Table 2 and Fig. 2 
Table 2. Frequency of discussions with parents about intimate relationships

\begin{tabular}{|c|c|c|c|}
\hline & Rare & Some times & $\begin{array}{c}\text { frequ } \\
\text { ently }\end{array}$ \\
\hline 9th grade & 8 & 5 & 5 \\
\hline 10th gade & 7 & 10 & 4 \\
\hline 11th grade & 3 & 13 & 4 \\
\hline 12th grade & 8 & 13 & 3 \\
\hline
\end{tabular}

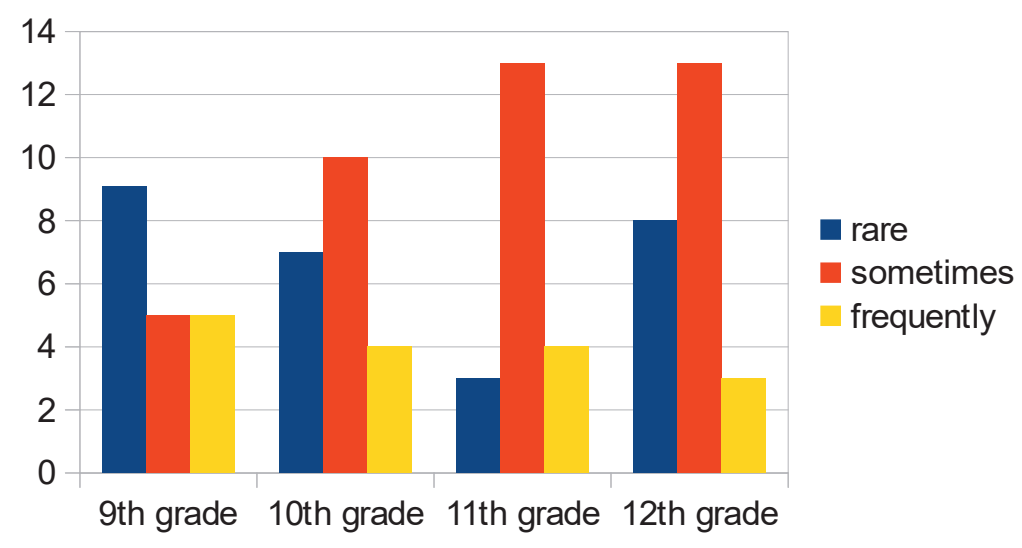

Fig. 2.Frequency of discussions with parents about intimate relationships

At all age levels, few are the ones who frequently discuss this subject with their parents (about a third or a quarter of those who discuss the subject). Most of them only talked only sometimes, and the others rare. Approaching the subject probably happened when adolescents had some concerns, or when the parents approached the subject, considering the it is the age at which should be discussed with the children this issue.

Many families still retain the idea and conception of a subject that should not be discussed în front of the children or with them. In addition, unjustified insane embarrassment transmitted to children at so-called "shameful" aspects prevent the establishment of a comradely and continuous relationship between the two generations. This was also reflected in the answers to the next question, on how open the discussions with parents were on this issue (see Table 3). 
Table 3. How open the discussions with parents were

\begin{tabular}{|c|c|c|c|}
\hline & $\begin{array}{c}\text { any } \\
\text { thing }\end{array}$ & $\begin{array}{c}\text { neutral } \\
\text { subjects }\end{array}$ & $\begin{array}{c}\text { I'm not } \\
\text { talking } \\
\text { about it }\end{array}$ \\
\hline 9th grade & 10 & 11 & 1 \\
\hline 10th gade & 10 & 9 & 1 \\
\hline 11th grade & 16 & 5 & 1 \\
\hline 12th grade & 13 & 10 & 3 \\
\hline
\end{tabular}

A large number of adolescents (almost half, 49) says they can discuss anything with their parents who are open and understanding. However, an equally large number (41 pupils) of those who answered this question argue that their discussions with parents are limited to neutral subjects that do not refer to their intimate life or do not address the subject at all.

Parents-teenagers relationships have not yet reached a degree of openness and acceptance that is sufficiently convenient for adolescents. Some barriers to the role and status of parents continue to exist today, which is why one third of the subjects do not even want to talk to parents about it.

Thirty-three of the subjects do not want to talk to their parents, instead 64 of them would like to have open talks with them. Significantly, as psychosocial maturation (also reflected in the passage from one cache to another), there is a growing number of people who would like to discuss with their parents about their problems.Ultimately, even if they are not specialists in the field, parents are always close to adolescents, have knowledge acquired through their personal life experience and can answer many of their questions.

The fact that parents, not school, is the source of information for students in this field is also evidenced by the answers to another question, which are categorical when they say that there is no school education program for pupils (Table 4 and Fig. 3)

Table 4. The existence of sexual education hours în curriculum

\begin{tabular}{|c|c|c|}
\hline & Yes & No \\
\hline 9th grade & 5 & 19 \\
\hline 10th gade & 3 & 24 \\
\hline 11th grade & 0 & 22 \\
\hline 12th grade & 6 & 21 \\
\hline
\end{tabular}




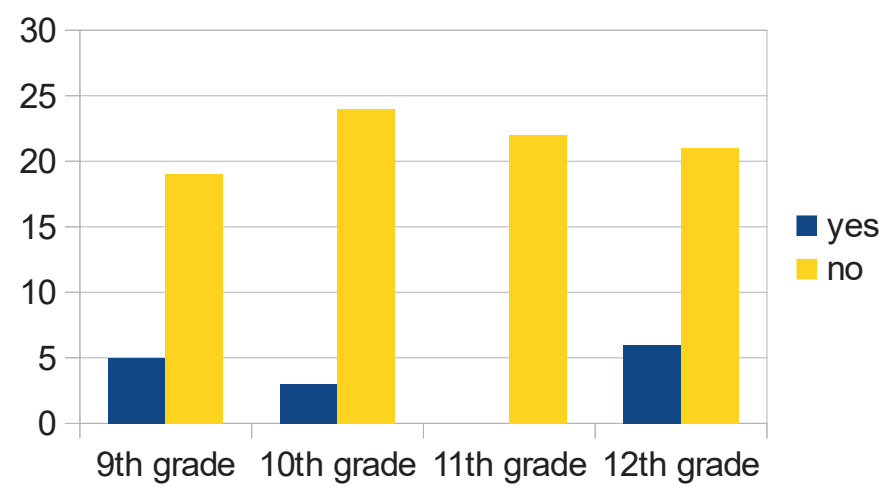

Fig. 3. The existence of sexual education hours in the curriculum

It is clear the subjects opinion about school sexual education hours: these are completely absent. Those who responded affirmatively to this question probably interpreted some topics from biology or conducting classes as sexual education classes. Unfortunately, the Romanian school does not deal with the pupils' life skills (including knowledge about life and sexual hygiene), but, later it can not explain the cases of school dropouts or teenage mothers.

The interest in such information is increased for high school students who, given the multiple biological and psychological transformations in adolescence, need reliable, clear and scientific information explaining the time they cross and its implications. (Table 5)

Table 5. Interest în hours of sexual education

\begin{tabular}{|c|c|c|c|}
\hline & Yes & somewhat & No \\
\hline 9th grade & 13 & 10 & 1 \\
\hline 10th gade & 9 & 15 & 3 \\
\hline 11th grade & 12 & 8 & 2 \\
\hline 12th grade & 12 & 12 & 3 \\
\hline
\end{tabular}

Many adolescents are interested in introducing such lessons into the curriculum. Those 46 who are very interested can say this because they do not have any information, they have no one to discuss with them, or they want to enrich their knowledge in the field also with the opinion of specialists. Students who are somewhat interested may have some of the information that they consider insufficient, hence their partial interest in this type of lesson. Finally, students who are not at all interested in such classes 
either consider that they have all the information they need or do not want to address such a topic that they find embarrassing, especially if the discussions take place in plenary (all class boys and girls) and not separately by gender.

The maintenance of intimate relationships and their frequency are presented in Table 6.

Table 6. Frequency of sexual relations

\begin{tabular}{|c|c|c|c|c|}
\hline & Never & Rare & Occasionally & $\begin{array}{c}\text { Frequ } \\
\text { ent }\end{array}$ \\
\hline 9th grade & 20 & 10 & 1 & 2 \\
\hline 10th gade & 20 & 1 & 4 & 2 \\
\hline 11th grade & 8 & 2 & 8 & 4 \\
\hline 12th grade & 9 & 2 & 8 & 8 \\
\hline
\end{tabular}

More than half of adolescents (57 subjects) did not have sex until they were questioned, and few of them (16) say they have frequent sexual intercourse. It could be a proof that adolescents are not too concerned with sexuality and still tatters the ground to confirm whether they are happy with this type of relationship and whether to continue them.

The sources of information that teens use are different and vary quite a bit. Most of them use two sources in association (parents and the internet or friends and the internet) (see Table 7 and Fig.4).

Table 7. Adolescents information sources

\begin{tabular}{|l|l|}
\hline Sources & Number \\
\hline TV & 17 \\
\hline Internet & 34 \\
\hline Parents & 40 \\
\hline Friends & 35 \\
\hline School & 21 \\
\hline Others & 5 \\
\hline
\end{tabular}


Fig. 4. Adolescents informations sources

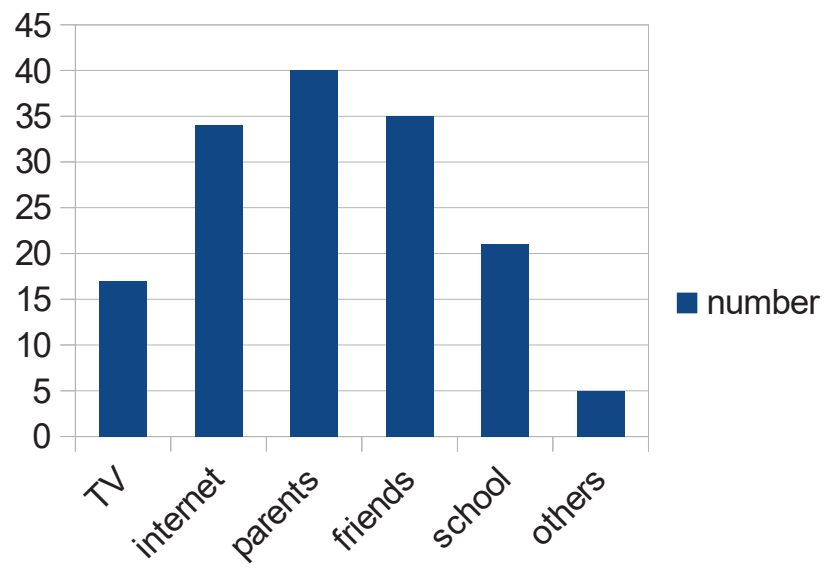

It must be admitted, unfortunately, that school is not one of the main sources of information used by teenagers about contraceptive methods. The first three places are the parents (with 40 references), friends (with 35 entries) and the internet (with 34 entries). In most cases, however, two sources of information are used in parallel, as mentioned above.

The school is ranked number four with 21 entries, followed by television with 19 titles. There were also five cases that did not opt for any of the sources of information mentioned in the questionnaire and responded with "others" specifying the books in 3 cases and the doctor in the other two cases. Importantly, young people are trying to document and gather information about a problem that concerns them and interests them. Less commendable is the effort of the school to provide the necessary information for adolescents, leaving everything to parents, friends and the Internet.

In our opinion, the school would be best placed to provide real, scientific information. Information obtained from parents or friends is often based on each person's personal experience or level of knowledge they have. On the Internet, the scientific character of the information is higher, but not all teenagers have computer and internet at home. That is why the role of the school should be much larger and this institution should be more actively involved in the sexual education of the younger generation.

It should also be noted that a very small number of subjects contacted the gynecologist for specialist consultation (6 cases from the studied group) (see Table 8).

Table 8. Consulting a gynecologist

\begin{tabular}{|c|c|c|}
\hline & Yes & No \\
\hline 9th grade & 2 & 20 \\
\hline
\end{tabular}


Journal Plus Education, ISSN: 1842-077X, E-ISSN (online) 2068-1151 Vol XIX (2018), No. 1. pp. 249-261

\begin{tabular}{|c|c|c|}
\hline 10th gade & 0 & 27 \\
\hline 11th grade & 1 & 21 \\
\hline 12th grade & 3 & 24 \\
\hline
\end{tabular}

It is gratifying that although they have not always used the methods of protection, although they had more than three partners in their relationships, adolescents studied by us did not face major risks and were required to call a specialist doctor only in 6 cases out of 100 subjects. We are dealing with a positive signal about the personal hygiene of the subjects and the relationships they have maintained.

\section{Conclusions}

The research has led to the following conclusions: adolescents generally discuss with their parents the issues related to sexual life. Half of the subjects have open talks with their parents in this regard, the other half prefer neutral talks or not talk to parents at all. Hence the need to set up counseling boards in high schools to provide teenagers with all the information they need and where they are aware that they can talk absolutely with confidence.

Most of the information that teenagers have about sexual life and hygiene comes from parents, friends and the internet. Unfortunately, the information, especially those provided by parents and friends, is not scientific in nature, usually based on the personal experience of the person providing the information. In this way, teenagers often get erroneous information, or perpetuate misconceptions and mentalities which hampers the development and adaptation of adolescents.

That is why many of the subjects still consider sexual life as a topic of taboo discussion, or as a gossip theme. Appropriate counseling by specialists in the field would reduce these impediments and a more realistic approach to sexual life issues.

It must be not forgetten that much of the number of divorces today (a growing number) is due to communication difficulties and those in the sphere of sexual life. If adolescents are not taught to talk realistically about their sexual problems, it is unlikely that in their couple lives they will be able to communicate with their partner.

We believe that the establishment of sexual life counseling centers could clearly contribute to improving the future social and family adaptation of adolescents, leading to a decrease in the number of divorces over time. At the same time, as a direct effect, such counseling could lead to the avoidance of unwanted pregnancies in adolescents. Perhaps, in fact, counseling should be begun from the gymnasium, when the preadolescents have neither the 
ability to understand the consequences of their actions, nor the information necessary for knowing the physiological phenomenon, nor the responsibility or ability to raise a child.

Romanian education should take into account the increasingly alarming statistics that are being circulated in the media and try to regain some of the lost ground in this field.

Acknowledgement: We hereby state that the subjects involved in our research were informed about the voluntary character of participation in this research, about the understanding of information and of that fact that withdrawal from research is possible at any time without negative consequences upon the participant. The research complied with all ethical research standards, the research participants/participants' guardians giving their consent to participate in the research.

\section{References}

David, D. (2014). Dezvoltare personala și sociala. Iasi: Editura Polirom

Dincă, M. (2004).Adolescenţii într-o societate în schimbare, Bucureşti: Editura Paideia

Fodoreanu, L. (2004). Psihiatrie. Cluj-Napoca: Editura Medicală Universitară"Iuliu Haţieganu"

Galimard, P. (2015). Psihologia adolescentului de la 11 la 15 ani. Bucureşti: Editura Meteor

Golu, F. (2015). Manual de psihologia dezvoltarii. Iasi: Editura Polirom

Hoyle, R.H. (2014). Handbook of Personality and self-Regulation, John Wiley and Sons Ltd., Oxford

Modrea, M. (2006). Imaginea de sine şi personalitatea în adolescenţă. Studii teoretice şi experimentale. Focşani: Editura Aliter

Moldovan, O.D., Bălas-Timar, D. (2010). Psihologia adolescenţei şi vârstei adulte. Arad: Editura Universităţii Aurel Vlaicu

Popa-Velea, O. (2013). Ştiinţele comportamentului uman, Bucureşti: Editura Trei

Verza, E. (2000). Psihologia vârstelor. Bucureşti: Editura Pro Humanitate 